\title{
Role of Mental Disorders in Nosocomial Infections after Hip Fracture Treatment
}

\author{
Enrique Guerado, ${ }^{1}$ Juan Ramon Cano, ${ }^{1}$ Encarnacion Cruz, ${ }^{1}$ Nicolás Benitez-Parejo, ${ }^{2}$ \\ and Emilio Perea-Milla ${ }^{2}$ \\ ${ }^{1}$ Department of Orthopaedic Surgery and Traumatology, Hospital Costa del Sol, University of Malaga, Marbella, 29603 Málaga, Spain \\ ${ }^{2}$ Department of Research, Statistics, and Epidemiology, CIBERESP, Hospital Costa del Sol, University of Malaga, \\ Marbella, 29603 Málaga, Spain
}

Correspondence should be addressed to Enrique Guerado, eguerado@hcs.es

Received 19 August 2009; Revised 12 December 2009; Accepted 5 April 2010

Academic Editor: Kenrad Nelson

Copyright (c) 2010 Enrique Guerado et al. This is an open access article distributed under the Creative Commons Attribution License, which permits unrestricted use, distribution, and reproduction in any medium, provided the original work is properly cited.

The association between mental disorders (MDs) and iatrogenic complications after hip fracture surgery has been poorly studied. Among iatrogenic complications, nosocomial infections (NIs) are a major factor in hip fracture surgery. The aim of this paper was to determine whether patients with a MD and a hip fracture develop more NIs after hip surgery than patients with no MD. We studied 912 patients who underwent surgery for a hip fracture (223 patients with a MD who underwent surgery for a hip fracture and 689 control patients without a MD who also underwent surgery for a hip fracture) and followed them after surgery. Univariable and multivariable analyses were performed using simple and multiple logistic regression analysis (confidence interval, crude and adjusted odds ratios, and $P$ value). We found that MDs, gender, and comorbidities were not associated with a higher risk of developing a NI after surgery for a hip fracture. Only age increases the risk of a NI.

\section{Introduction}

Falls are a major cause of morbidity and mortality in older people with cognitive impairment; further, a high percentage of patients with a mental disorder (MD) fall repeatedly before fall-related hip fractures [1-3]. However, once a hip fracture has occurred, the risk factors for a poorer survival prognosis are co-morbidities, age older than 85 years, male sex, dependent living arrangements, and a diagnosis of dementia $[4,5]$.

Concomitant depression and dementia significantly increase the 12-month risk of elderly patients dying after surgery for a hip fracture [6]. Cognitive and mood disorders are common in elderly patients with a hip fracture and are associated with greater risk of poor outcomes, both independently and in combination. Recognition and treatment of these conditions together with stratification of variables associated with these disorders may reduce adverse outcomes in this vulnerable population [7]. Since surgery to treat hip fractures is considered the gold standard even for nonagenarians with a heavy co-morbidity burden [8], a study to determine an association between surgical complications and a MD appears to be extremely important; nevertheless, the association between a MD and iatrogenic complications after hip fracture surgery has not been addressed adequately. Among iatrogenic co-morbidities, nosocomial infections (NIs) are a major problem after hip fracture surgery; because of the morbidity and mortality, the surgeon is always aware of this devastating complication.

The aim of this paper was to study whether patients with a MD and a hip fracture develop more infections after hip surgery than patients without a MD. Because MDs are not only a common cause of hip fractures but also of complications after surgery, we addressed the hypothesis that patients with a MD develop more infections after surgery for hip fractures than patients without a MD. The null hypothesis is that there is no difference between the groups, and the alternative hypothesis is that patients with a MD and a fractured hip develop fewer infections than those without a MD. 


\section{Material and Methods}

2.1. Data. We designed a cohort study of patients with a MD who underwent surgery for a hip fracture and a control group of patients without a MD who also underwent surgery for a hip fracture. We followed them after surgery to study the differences in the rates of development of NIs. We reviewed the records of all patients who underwent hip fracture surgery in our institution between 2006 and 2008 . Data on all hip fractures were collected prospectively from the patient admission. The data collection was based on the Minimum Data Base Group of the Spanish National Health System [9] and followed the Standardised Audit of Hip Fractures in Europe (SAHFE) [10]. Data management was protected by the Spanish data protection law [11] and overallprocedures was supervised by the ethics committee of our hospital. The affiliation, full clinical history, and complications were included in our hospital database; we worked only with computerized clinical histories (HP Doctor Hewlett-Packard Española SA 2001. License HCE 2001). Two authors collected the data from our database. However, since all data were computerized and codified, the potential for biased interpretation was eliminated.

2.2. Mental Disorders. Although all elderly patients admitted to our department underwent the Mini-Mental Test (MMT) [12], performed by a nurse, on ward admission, we considered a MD as any behavioural disturbance that was professionally diagnosed or corroborated by the Psychiatry Department of our hospital. Proper diagnosis for codification had to be made by a specialized doctor. According to the International classification of Diseases, Tenth Edition (ICD10-CM), the diagnoses included nonbehavioural-alteration dementia, senile dementia without complications, vascular dementia with no complications, Alzheimer's disease, Parkinson's disease, alcoholism, unclassified depression, and other forms of anxiety and dissociative or somatomorph disorders.

2.3. Treatment. All patients received prophylactic intravenous antibiotics 30 minutes before surgery ( 2 grams of sodium cefazoline) and two additional doses during the next 2 days. In patients allergic to penicillin, 1 gram of vancomycin was administered. We did not use antibioticimpregnated implants or gentamicin-impregnated bone cement. Most patients had spinal anaesthesia, and no patient underwent a simultaneous bilateral surgery. A group of staff surgeons experienced in treating hip fractures performed all surgeries. Since the objective of this study was to address the end point of infection or no infection, we considered both osteosynthesis and joint replacement techniques. Osteosynthesis consisted of either $\mathrm{AO}$ cannulated screws $(5 \mathrm{~mm}$ cannulated screw Synthes), a proximal femoral nail (PFN, Synthes), or a joint replacement (either a partial or a total cemented hip replacement) (Exeter, Stryker). Patients were not assigned to any treatment based on mental, social, or any factors other than femoral head viability and general health.

Patients in good general health underwent osteosynthesis; patients with worse general health underwent joint replacement; those with very poor general health underwent partial joint replacement. Patients were classified by comorbidity according to the criteria of Charlson et al. [13]. The Charlson Index contains 19 categories of co-morbidities, originally based on ICD-9-CM diagnoses and procedural codes, and their associated weights, that provide an overall co-morbidity score to reflect the cumulative increased likelihood of 1-year mortality. We regrouped the criteria of Charlson et al. into three groups according to the studies of Deyo et al. [14] and Romano et al. [15]. The original groups 0 to 7 , for which 0 indicated the least and 7 the most severe, were regrouped into 0 to 2 (category 2 included categories $2-7$ ). Categories also were based on the ICD-10-CM and the version of Librero et al. [16]. For surgical indication, we did not make a mathematical correlation between the groups of Charlson et al. and the type of treatment. Because patients did not know that research was in progress, all were considered randomized; further, doctors were on call based on an already scheduled timetable to perform a similar number of surgeries. Therefore, the patients did not choose the doctors. The chance of being operated on by a specific surgeon was the same for groups A and B described below.

2.4. Nosocomial Infections. We considered a NI as any infection that developed within 3 months after the primary surgery for a hip fracture (infection either at the surgical site, pneumonia, urologic infection, or others). Classically, the topography of infection at the surgical site includes either deep or superficial infection, depending on whether the infection is deep or superficial to the fascia lata. Since this classification is based on surgeon inspection, we believe that the sensitivity is very low, therefore in most cases we treated the infection thoroughly as a deep one. For this research, diagnosis of a NI was based on a retrospective analysis of our database. Retrospective analysis of the clinical history is the most sensitive and specific method for infection diagnosis [17], although primary detection was based on a positive bacteriologic culture. Patients either with a followup shorter than 1 year or patients who died postoperatively before 3 months for a reason other than a NI were excluded. Therefore, we were certain that all patients, whether they had a MD or not, had the same chance of developing a NI. Any patient with a mechanical complication such as "cut out" of implants (loosening of the implant), a periprosthetic fracture, or any other reintervention also was excluded provided that the patient had not developed an infection as a result of the first surgery.

2.5. Design. The main cohort of patients included those who underwent surgery for a hip fracture with a previous diagnosis of MD (group A). The control group included patients who underwent surgery for a hip fracture without a previous diagnosis of a MD (group B). Since the aim of this study was to determine the association between a $\mathrm{MD}$ and postoperative infection, it was especially important that the diagnosis of a MD was established before surgery. Age, gender, and length of hospital stay (LOS) also were studied. 
2.6. Statistical Analysis. Data were transported, coded, and stored in a Microsoft Excel programme (Windows 2007, Microsoft Corp., Redmond, WA) and analyzed using a SPSS programme (version 14.0 SPSS Inc., Chicago, IL). The primary end point was the development of a NI during the hospital stay. The mean and $95 \%$ confidence intervals (CIs) were calculated for the quantitative variables, and percentages were calculated for the qualitative variables. A univariate analysis was performed using a simple logistic regression model to estimate the odds ratio (OR) and the corresponding 95\% CI. Multiple logistic regression analysis was then performed to adjust for the effect of a MD on age, sex, and the index of severity of Charlson et al. [13-15].

\section{Results}

We enrolled 912 patients who underwent surgery for a hip fracture. Group A (patients with a previous diagnosis of a MD) included 223 patients; group B (patients without a previous diagnosis of a MD) included 689 patients.

\subsection{Univariate Analysis (Table 1)}

3.1.1. Age. The patients in group A were an average age of 78.82 years. Although the range was between 0 and 100 years, $95 \%$ of the patients were between 57.26 and 100.38 years. The patients in group B were an average age of 75.81 years. The range also was considered to be between 0 and 105 years, and $95 \%$ of the patients were between 47.15 and 104.46 years.

3.1.2. Gender. The patients included 647 (70.94\%) women and 265 men $(29.05 \%)$ (group A, 68 men [30.49\%] and 155 women [69.51\%]; group B, 197 men [28.59\%] and 492 women [71.41\%]).

3.1.3. MD. Group A included 223 patients (24.45\%), and group B included 689 patients (75.54\%).

3.1.4. Comorbidities. A total of 821 patients (88\%) were classified, based on the criteria of Charlson et al., in group 0 or 1 and $91(10 \%)$ in group 2 (group 2 included groups 2 to 7 according to the modified criteria of Charlson et al. [13-16]). Therefore, most patients had a less severe score for the criteria of Charlson et al. The mean value for the score of Charlson et al was 0.60. Groups A (presence of a MD) and B (no MD) were matched according to the criteria of Charlson et al. $79.82 \%$ of group A patients were in the $0-1$ group of Charlson et al. and $93.33 \%$ were in group B. Therefore, the comorbidities did not differ between groups.

3.1.5. Infection. A NI developed in 58 patients $(6.4 \%)$ of all 912 patients. Twelve out of 223 patients (5.38\%) were in group A; 46 of 689 (6.68\%) were in group B. Although patients with a MD had fewer infections than patients without a MD, the difference was not significant (OR, 0.795; CI, $96.5 \%=0.413-1.529 ; P=.49)$. The results of simple and multiple logistic regression analyses are shown in Table 2. The distribution of microorganisms and infection sites in groups A and B are shown in Table 3.
3.1.6. Length of Stay. The median preoperative LOS in group A was 1.96 days (range, $0-8$ ) and in group B 1.51 days (range, $0-9)$. The overall mean LOS was 8.30 days. In group A, the total LOS was 7.09 days (CI, 6.34-7.83) and in group B 8.74 days (CI, 8.00-9.48). The total LOS for patients in group A who developed a NI was 13.58 days (standard deviation [SD], 16.79), whereas for patients in group B with a NI the LOS was 28.08 days (SD, 21.96). The LOS in group A decreased dramatically to 6.72 days $(\mathrm{SD}, 4.08)$ when patients did not develop a NI and to 7.35 days $(\mathrm{SD}, 6.45)$ in group B. One patient in group A with a NI was discharged to a nursing home and seven to their own home; four patients died from the NI. In group B, five patients were discharged to a nursing home, 33 to their own home, one back to her country, and seven died because of the NI. There was no statistical difference between groups in mortality.

3.2. Multivariate Analysis. The results of multivariate analyses are shown in Table 2. MDs were not associated with infection when considered alone (crude OR, 0.79; 95\% CI, 0.413 ; 1.529) or together with the other variables (multivariate analysis, adjusted OR, $0.74,95 \%$ CI, $0.37 ; 1.46$ ).

Age was associated with infection when considered alone (crude OR, 0.96; 95\% CI, 0.95; 0.97) or together with other variables (multivariate analysis, adjusted OR, 1.04; 95\% CI, $1.01 ; 1.07)$.

Gender was not associated with infection when considered alone $(\mathrm{OR}=0.93 ; 95 \% \mathrm{CI}, 0.51 ; 1.68)$ or together with other variables $(\mathrm{OR}=1.14[0.62 ; 2.10])$. The differences were not significant.

The criteria of Charlson et al. for co-morbidities were not associated with infection when considered alone (crude OR for index 1, 1.07 [95\% CI, 0.60; 1.90], and for index 2, which included 2 to $7, \mathrm{OR}=1.07$ [95\% CI, $0.43 ; 2.65]$ or together with other variables (multivariate analysis, adjusted OR for index 1, 0.99; [95\% CI, 0.54; 1.80], for index 2, which included 2 to 7 ; OR, 1.02 [95\% CI, 0.40; 2.62].

\section{Discussion}

Considering the outcomes of hip fracture after treatment, infection is a major issue in morbidity and mortality [4, $18,19]$. Apparently, many variables appear to be associated with infection; age, male sex, type of fracture and treatment, and many others which have or have not been shown to be associated with infection [20]. Studies of these issues should be addressed by considering infection as a nosocomial disease rather than only a surgical-site disease, since morbidity and mortality associated with nonsurgical-site infection justify this approach. However, the methodology should be designed such that many variables can be associated with each other; therefore, multivariate analysis is of overwhelming importance in these studies [21-25].

In the current paper, $24 \%$ of our patients had a MD, which may represent a very low frequency; however, we measured the prevalence and not the incidence of MD. We followed patients with and without a MD by the time of admission (prevalence) who can develop an infection during follow-up (incidence). We believe the professional diagnosis 
TABle 1: Descriptive statistics for Groups A (patients with mental disorders) and B (patients without mental disorders).

\begin{tabular}{|c|c|c|c|c|c|c|c|}
\hline \multirow{3}{*}{ Variables } & & \multicolumn{6}{|c|}{ Mental disorder } \\
\hline & & \multicolumn{3}{|c|}{ (GROUP A: patients with mental disorders) } & \multicolumn{3}{|c|}{ (GROUP B: patients without mental disorders) } \\
\hline & & without Infection & Infection & Total & without Infection & Infection & Total \\
\hline $\begin{array}{l}\text { Length of } \\
\text { stay (days) }\end{array}$ & & $6.72(4.08)^{*}$ & $13.58(16.74)^{*}$ & $7.09(6.34 ; 7.83)$ & $7.35(6.45)^{*}$ & $28.08(21.96)^{*}$ & $8.74(8.00 ; 9.48)$ \\
\hline Age (years) & & $78.45(11.14)^{*}$ & $84.83(5.75)^{*}$ & $78.82(57.26 ; 100.38)$ & $75.50(14.89)^{*}$ & $80.15(8.16)^{*}$ & $75.81(47.15 ; 104.46)$ \\
\hline $\begin{array}{l}\text { Charlson et } \\
\text { al. }\end{array}$ & 0 & $63(20.9 \%)$ & $2(16.7 \%)$ & $65(29.15 \%)$ & $407(63.4 \%)$ & $29(63.0 \%)$ & $437(63,43 \%)$ \\
\hline index for & 1 & $106(50.2 \%)$ & $7(58.3 \%)$ & $113(50,67 \%)$ & $192(29.9 \%)$ & $14(30.40 \%)$ & $206(29,9 \%)$ \\
\hline comorbidity & $2+$ & $42(19.9 \%)$ & $3(25.0 \%)$ & $45(20.18 \%)$ & $43(6.7 \%)$ & $3(6.6 \%)$ & $46(6,68 \%)$ \\
\hline \multirow{2}{*}{ Gender } & Male & $63(29 \%)$ & $5(41.7 \%)$ & $68(30.49 \%)$ & $186(28.9 \%)$ & $11(23.9 \%)$ & $197(28,59 \%)$ \\
\hline & Female & $148(70.1 \%)$ & $7(50.3 \%)$ & $155(69.51 \%)$ & $457(71.1 \%)$ & $35(76.1 \%)$ & $492(71,50 \%)$ \\
\hline \multirow{3}{*}{$\begin{array}{l}\text { Nosocomial } \\
\text { infection }\end{array}$} & No & & & $211(94.62 \%)$ & & & $643(93.32 \%)$ \\
\hline & Yes & & & $12(5.38 \%)$ & & & $46(6.68 \%)$ \\
\hline & & & & Total: $223(24.5 \%)$ & & & Total: $689(75.05 \%)$ \\
\hline
\end{tabular}

For continous variables, mean and 95\% CI.

For discrete variables, frequency and percent.

* Standard deviation.

TABLE 2: Simple and multiple logistic regression (crude OR and adjusted $\mathrm{OR}^{*}$ ) for nosocomial infection.

\begin{tabular}{lccc}
\hline Variables & & Crude OR $(95 \%$ CI $)$ & Adjusted OR (95\% CI) \\
\hline Mental disorders & No* & 1 & 1 \\
Mental disorders & Yes & $0.79(0.41 ; 1.53)$ & $0.74(0.37 ; 1.46)$ \\
Age & & $0.96(0.95 ; 0.97)$ & $1.04(1.01 ; 1.07)$ \\
Charlson et al. & $0^{*}$ & 1 & 1 \\
index for & 1 & $1.07(0.60 ; 1.90)$ & $0.99(0.54 ; 1.80)$ \\
comorbidities & $\geq 2$ & $1.07(0.43 ; 2.65)$ & $1.02(0.40 ; 2.62)$ \\
Gender & Male* & 1 & 1 \\
& Female & $0.93(0.51 ; 1.68)$ & $1.14(0.62 ; 2.10)$ \\
\hline
\end{tabular}

${ }^{*}$ Reference value.

may be the key and tried to avoid subjective diagnoses by relatives, nurses, or orthopaedic surgeons. Further, we saw that in most studies this concept is very confusing, and too many patients are included as having a MD. The MMT is carried out by nurses and probably a magnification of the problem exists. It has been shown that patients living in nursing homes fall more than those living with their families; moreover, they can develop more MDs $[2,3]$. However in the current study, we studied the prevalence of MDs independent of patients origin and their risk of a NI after surgery.

We used a multiple logistic regression model to study 912 patients who underwent surgery for a hip fracture. We considered a MD as the main variable to be verified by statistical analysis. MD is a risk factor for hip fracture and apparently for a poor outcome after the diagnosis has been made $[4,5,7,20,26-30]$. Nevertheless, to the best of our knowledge, the effect of the association of infection together with a MD has not been studied. Since the rate of development of a NI in patients with a previous MD could be very high, and the question arises about whether it is very risky or even practical for these patients to undergo surgery, we designed a cohort study in patients with a previous diagnosis of a MD who sustained a hip fracture and underwent either osteosynthesis or joint replacement. We conducted a literature search for infection as a complication of surgical treatment or hospital stay. Our results showed that there was no association between a MD and NI. Moreover, multiple logistic analyses showed that development of a NI in patients with a MD was not associated with age, gender, or comorbidities. Only age was an independent variable associated with a higher risk of development of a NI.

Previous reports have studied variables by performing univariate analysis and excluding some confounding variables $[18,19]$. Consequently some associations can be overestimated by the effect of those variables. That probably also is true for the role of co-morbidities, according to the criteria of Charlson et al.; up to $90 \%$ of our patients were in groups 0 and 1, and, surprisingly, analyses showed that there was no significant association between the criteria of Charlson et al. [13] for comorbidities and NIs. This was 
TABLE 3: Bacterial culture results.

\begin{tabular}{|c|c|c|c|c|c|c|c|c|c|c|}
\hline & & Surgical Site & & Pneumonia & & & Urinary & & Others & Total \\
\hline & No. & Bacteria & $n$ & Bacteria & & $n$ & Bacteria & & $n$ & \\
\hline \multirow{9}{*}{$\begin{array}{l}\text { Group A (patients } \\
\text { with Mental } \\
\text { Disorders) }\end{array}$} & \multirow{3}{*}{3} & $\begin{array}{l}\text { Staphylococcus } \\
\text { haemolyticus }\end{array}$ & 1 & Klebsiella Pneumoniae Blee + & 1 & \multirow{3}{*}{3} & M. morganii & 1 & \multirow{3}{*}{1} & \multirow{3}{*}{12} \\
\hline & & $\begin{array}{l}\text { St. galactiae and St. } \\
\text { epidermidis }\end{array}$ & 1 & E. aerogenes & 2 & & E. coli & 2 & & \\
\hline & & St. aureus & 1 & Common flora & 2 & & Non-filiated & 1 & & \\
\hline & & St. aureus & 3 & Ps. aeruginosa & 2 & & Klebsiella Pneumoniae Blee + & 1 & & \\
\hline & & St. haemolyticus & 1 & Acinetobacter baumanii & & 12 & St. aureus. & 1 & & \\
\hline & & $\begin{array}{l}\text { Enterococcus } \\
\text { faecalis }\end{array}$ & 6 & E. aerogenes & 3 & & E. coli & 5 & & \\
\hline & & Sarm & 2 & Common flora & 3 & & Ps. aeruginosa & 2 & 3 & 46 \\
\hline & & Escherichia coli & 6 & & & & E. asburiae & 1 & & \\
\hline & & $\begin{array}{l}\text { Morganella } \\
\text { morgagni }\end{array}$ & 1 & & & & St. sacarolyticus & 1 & & \\
\hline \multirow{7}{*}{$\begin{array}{l}\text { Group B (patients } \\
\text { without Mental } \\
\text { Disorders) }\end{array}$} & \multirow[t]{7}{*}{19} & St. epidermidis & 312 & & & & P. mirabilis & 1 & & \\
\hline & & $\begin{array}{l}\text { Pseudomona } \\
\text { aeruginosa }\end{array}$ & 3 & & & & & & & \\
\hline & & $\begin{array}{l}\text { Enterobacter } \\
\text { cloacae }\end{array}$ & 4 & & & & & & & \\
\hline & & $\begin{array}{l}\text { Klebsiella } \\
\text { pneumoniae }\end{array}$ & 3 & & & & & & & \\
\hline & & Proteus mirabilis & 3 & & & & & & & \\
\hline & & $\begin{array}{l}\text { Streptococcus } \\
\text { agalactiae }\end{array}$ & 1 & & & & & & & \\
\hline & & Ps. Fluorescens & 1 & & & & & & & \\
\hline
\end{tabular}

*Some cases had mixed infections with different bacteria.

also the case when multivariate analyses were performed for infection, the index of Charlson et al., and MDs. Grouping patients based on grade 2 or more of Charlson et al. would probably change those results. That is why when considering the American Society of Anaesthesiologists (ASA) score as the prognostic variable, patients with the physical status of ASA 3 or 4 have a poorer prognosis [20]. However, the accuracy of the prognosis according to the type of disease based on the criteria by Charlson et al. is much higher than ASA when managing the database [13-16].

We wish to clarify that although it could be suggested that if MDs were associated with a high NI rate (working hypothesis), orthopaedic surgeons may consider not performing surgery, but that was not the aim of the current study. Rather, if the working hypothesis was correct, a new project to identify patients with MDs at greater risk of developing a NI should be developed; then a discussion could take place about whether it is better not to operate, and a risk/benefit quotient could advise upon that.

However, in the current study and in other studies in this field, there are some limitations. By including some different diagnoses within the MDs, the relation of a particular MD with development of a NI can be underestimated. Current classifications within MDs include nonbehaviouralalteration dementia, senile dementia with no complications, vascular dementia with no complications, Alzheimer's disease, Parkinson's disease, alcoholism, unclassified depression, and other forms of anxiety and dissociative or somatomorph disorders (ICD-10 CM). Only a large multicentre study can differentiate between every mental diagnosis in a way that could stratify diagnoses without affecting possible statistical significance. Such a study, with multivariate analysis, could calculate the risk of developing a NI for every specific MD. Since the population under study would have to be extremely large, to our knowledge, no paper has addressed this problem for hip fracture.

Another problem when studying NIs is the likelihood of adding community-acquired infections; whether the patient developed the infection before or after the hospital stay is unknown when studying nonsurgical site infections. This problem is nearly impossible to solve; however, in the current paper, the chance of introducing this bias was the same for groups A or B. In fact, the earliest NI developed in both groups on the second hospital day. Therefore, we believe that the aim of this research was unaffected by that.

\section{Summary}

Patients with an MD do not have a higher risk of developing an NI after surgery for hip fracture than patients without 
an MD. An MD is not a significant protective variable (null hypothesis).

\section{Acknowledgments}

This paper was performed with a grant from the Carlos III Institute (The Spanish Ministry of Science and Innovation) to the authors' network of research group on Clinical Epidemiology (CIBERESP). The authors are grateful to Antonio Lara, and Francisco Rivas, for their assistance in data retrieval.

\section{References}

[1] P. Trimpou, K. Landin-Wilhelmsen, A. Odén, A. Rosengren, and L. Wilhelmsen, "Male risk factors for hip fracture-a 30year follow-up study in 7,495 men," Osteoporosis International, vol. 21, no. 3, pp. 409-416, 2010.

[2] F. Formiga, A. Lopez-Soto, E. Duaso, et al., "Characteristics of fall-related hip fractures in community-dwelling elderly patients according to cognitive status," Aging: Clinical and Experimental Research, vol. 20, no. 5, pp. 434-438, 2008.

[3] F. Formiga, M. Navarro, E. Duaso, et al., "Factors associated with hip fracture-related falls among patients with a history of recurrent falling," Bone, vol. 43, no. 5, pp. 941-944, 2008.

[4] K. B. Björkelund, A. Hommel, K.-G. Thorngren, D. Lundberg, and S. Larsson, "Factors at admission associated with 4 months outcome in elderly patients with hip fracture," American Association of Nurse Anesthetists, vol. 77, no. 1, pp. 49-58, 2009.

[5] C. de Luise, M. Brimacombe, L. Pedersen, and H. T. Sørensen, "Comorbidity and mortality following hip fracture: a population-based cohort study," Aging: Clinical and Experimental Research, vol. 20, no. 5, pp. 412-418, 2008.

[6] G. Bellelli, G. B. Frisoni, R. Turco, and M. Trabucchi, "Depressive symptoms combined with dementia affect 12months survival in elderly patients after rehabilitation posthip fracture surgery," International Journal of Geriatric Psychiatry, vol. 23, no. 10, pp. 1073-1077, 2008.

[7] J. L. Givens, T. B. Sanft, and E. R. Marcantonio, "Functional recovery after hip fracture: the combined effects of depressive symptoms, cognitive impairment, and delirium," Journal of the American Geriatrics Society, vol. 56, no. 6, pp. 1075-1079, 2008.

[8] E. Bergeron, L. Moore, K. Fournier, C. Gravel, and A. Lavoie, "Patients with isolated hip fracture must be considered for surgery irrespectively of their age, comorbidity status and provenance: a statement applicable even to nonagerians," Archives of Orthopaedic and Trauma Surgery, vol. 129, no. 11, pp. 1549-1555, 2009.

[9] "Registro de Alta de los Hospitales del Sistema Nacional de Salud. Ministerio de Sanidad y Consumo. CMBD. Norma Estatal," http://www.msc.es/estadEstudios/estadisticas/cmbd .htm.

[10] Scottish, http://www.shfa.scot.nhs.uk/.

[11] Ley Orgánica 15/1999, de 13 de diciembre, de Protección de Datos de Carácter Personal, http://noticias.juridicas.com/ base_datos/Admin/lo15-1999.t1.html.

[12] H. M. Hodkinson, "Evaluation of a mental test score for assessment of mental impairment in the elderly," Age and Ageing, vol. 1, pp. 233-238, 1972.

[13] M. E. Charlson, P. Pompei, K. L. Ales, and C. R. MacKenzie, "A new method of classifying prognostic co-morbidity in longitudinal series: development and validation," Journal of Chronic Disease, vol. 40, pp. 373-383, 1987.

[14] R. A. Deyo, D. C. Cherkin, and M. A. Ciol, "Adapting a clinical co-morbidity index for use with ICD-9CM administrative data," Journal of Clinical Epidemiology, vol. 45, pp. 613-619, 1992.

[15] P. S. Romano, L. L. Roos, and J. G. Jollis, "Adapting a clinical co-morbidity index for use with ICD-9-CM administrative databases: differing perspectives," Journal of Clinical Epidemiology, vol. 46, pp. 1075-1079, 1993.

[16] J. Librero, C. Cuenca, and S. Peiró, El Índice de Co-Morbilidad de Charlson. Aplicaciones en el CMBD, Quaderns de Salut Publica 18, Escuela Valenciana de Estudios para la Salud, Valencia, Spain, 2001.

[17] J. Vaque and J. Rosello, "Evolución de la Prevalencia de la Infecciones Nosocomiales en los hospitales españoles," EPINE, http://www.mpsp.org/mpsp/epine.

[18] J. Partanen, H. Syrjälä, H. Vähänikkilä, and P. Jalovaara, "Impact of deep infection after hip fracture surgery on function and mortality," Journal of Hospital Infection, vol. 62, no. 1, pp. 44-49, 2006.

[19] C. Edwards, A. Counsell, C. Boulton, and C. G. Moran, "Early infection after hip fracture surgery," Journal of Bone and Joint Surgery. British, vol. 90, no. 6, pp. 770-777, 2008.

[20] Y. Hasegawa, S. Suzuki, and H. Wingstrand, "Risk of mortality following hip fracture in Japan," Journal of Orthopaedic Science, vol. 12, no. 2, pp. 113-117, 2007.

[21] D. E. Grobbee and A. Hoes, Clinical Epidemiology: Principles, Methods, and Applications for Clinical Research, Jones and Bartlett, Boston, Mass, USA, 2009.

[22] A. Pickles, B. Maughan, and M. Wadsworth, Epidemiological Methods in Life Research, Oxford University Press, Oxford, UK, 2007.

[23] S. B. Hulley, S. R. Cummings, W. S. Browner, D. G. Grady, and T. B. Newman, Designing Clinical Research, Wolters Kluwer Lippincott Williams \& Wilkins, Philadelphia, Pa, USA, 2007.

[24] P. Webb, C. Bain, and S. Pirozzo, Essential Epidemiology: An Introduction for Students and Health Professionals, Cambridge University Press, Cambridge, UK, 2008.

[25] R. H. Fletcher, S. W. Fletcher, and E. H. Wagner, Clinical Epidemiology: The Essentials, Williams \& Wilkins, Baltimore, Md, USA, 2007.

[26] F. Formiga, A. Lopez-Soto, E. Duaso, et al., "Differences in the characteristics of elderly patients suffering from hip fracture due to falls according to place of residence," Journal of the American Medical Directors Association, vol. 8, no. 8, pp. 533537, 2007.

[27] S. D. Berry, E. J. Samelson, M. T. Hannan, et al., "Second hip fracture in older men and women: the framingham study," Archives of Internal Medicine, vol. 167, no. 18, pp. 1971-1976, 2007.

[28] N. Siddiqi, R. Stockdale, A. M. Britton, and J. Holmes, "Interventions for preventing delirium in hospitalised patients," Cochrane Database of Systematic Reviews, no. 2, Article ID CD005563, 2007.

[29] T. Rahkonen, H. Mäkelä, S. Paanila, P. Halonen, J. Sivenius, and R. Sulkava, "Delirium in elderly people without severe predisposing disorders: etiology and 1-year prognosis after discharge," International Psychogeriatrics, vol. 12, no. 4, pp. 473-481, 2000.

[30] D. J. Wood, G. K. Ions, J. M. Quinby, D. W. Gale, and J. Stevens, "Factors which influence mortality after subcapital hip fracture," Journal of Bone and Joint Surgery. British, vol. 74, no. 2, pp. 199-202, 1992. 


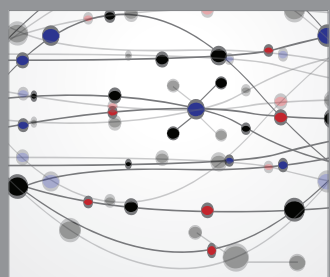

The Scientific World Journal
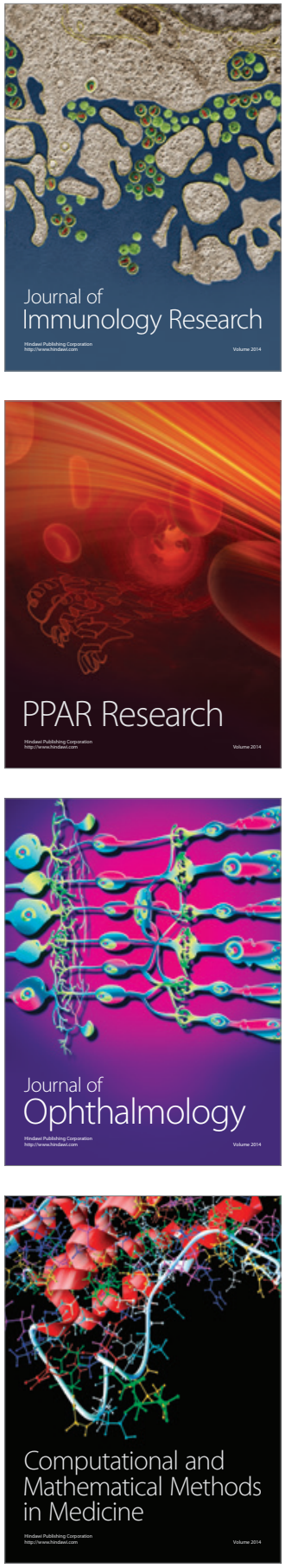

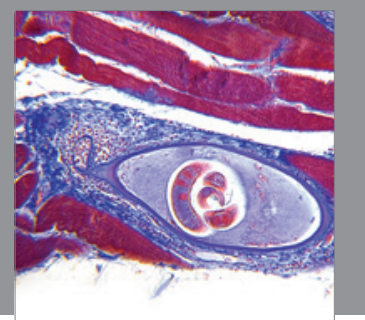

Gastroenterology

Research and Practice
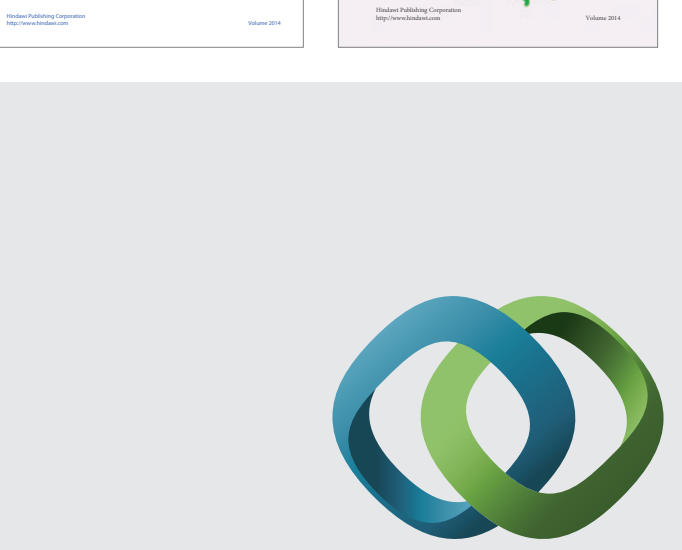

\section{Hindawi}

Submit your manuscripts at

http://www.hindawi.com
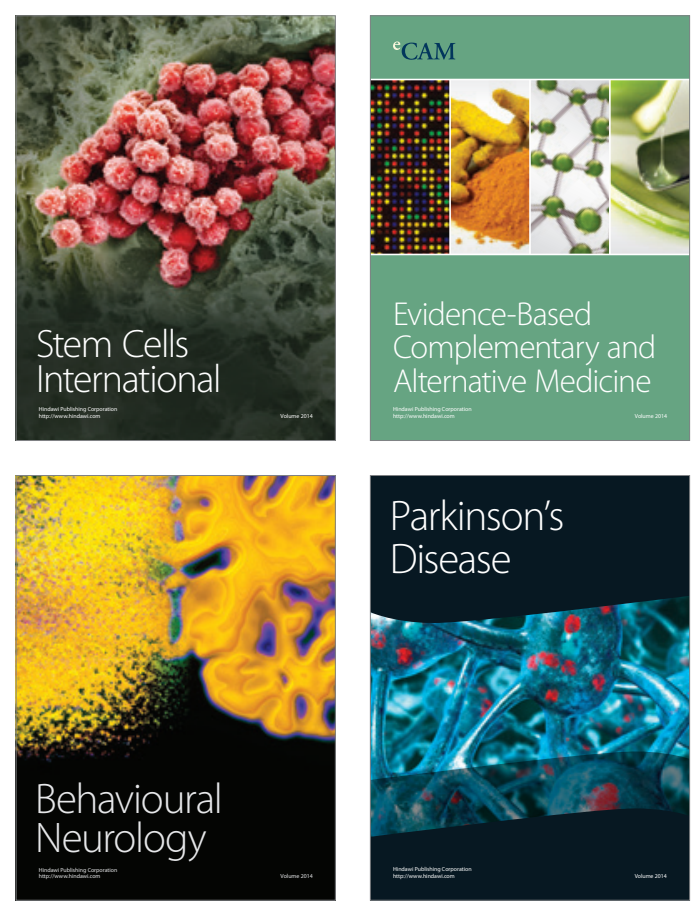

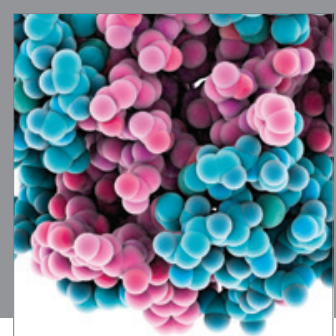

Journal of
Diabetes Research

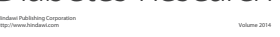

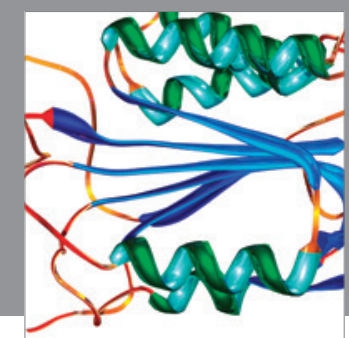

Disease Markers
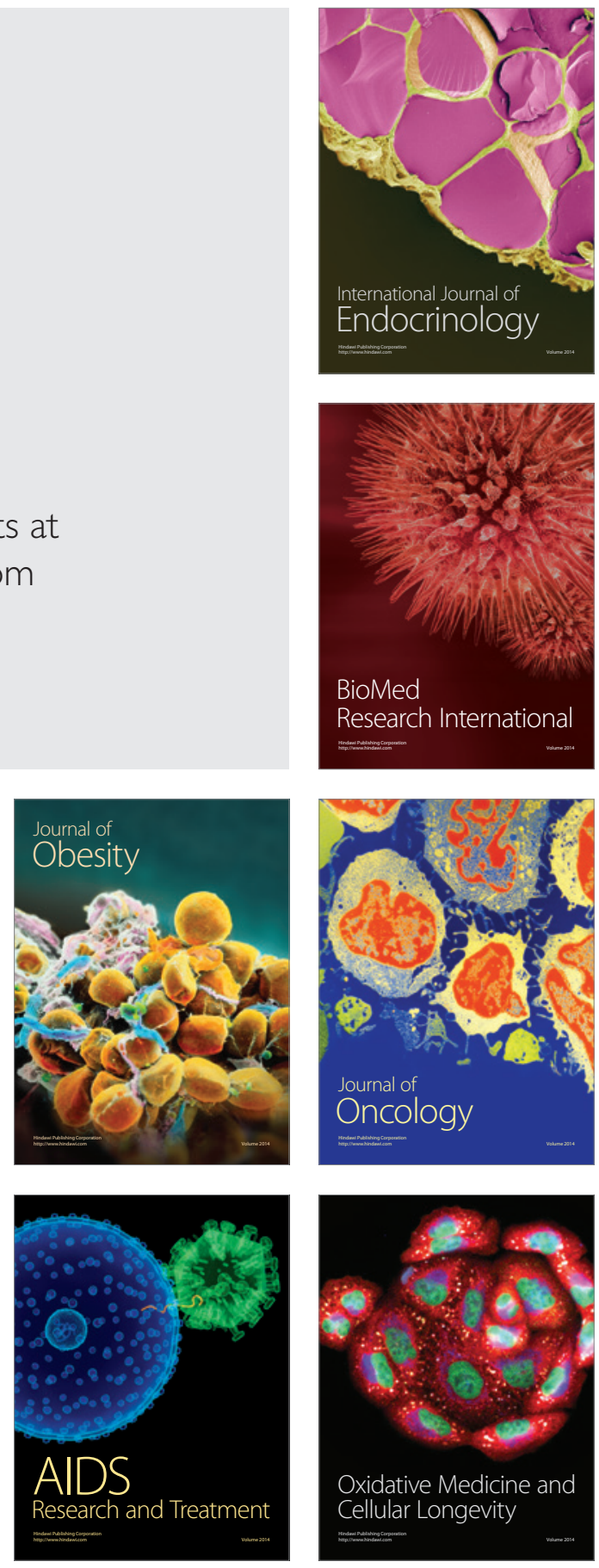